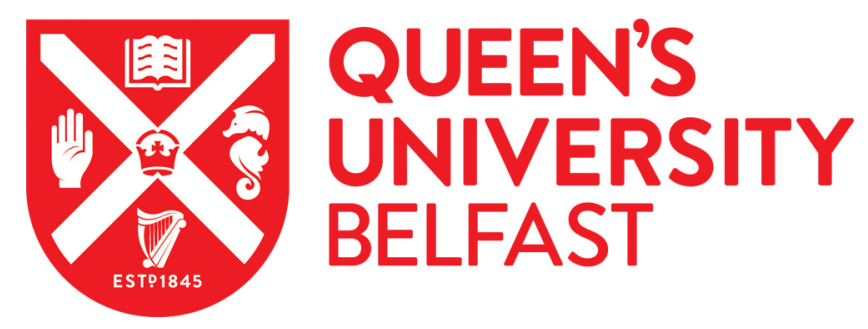

\title{
Seroprevalence of SARS-CoV-2 antibodies in children: a prospective multicentre cohort study
}

Waterfield, T., Watson, C., Moore, R., Ferris, K., Tonry, C., Watt, A., McGinn, C., Foster, S., Evans, J., Lyttle, M. D., Ahmad, S., Ladhani, S., Corr, M., McFetridge, L., Mitchell, H., Brown, K., Amirthalingam, G., Maney, J-A., \& Christie, S. (2020). Seroprevalence of SARS-CoV-2 antibodies in children: a prospective multicentre cohort study. Archives of Disease in Childhood, Early Online, 1-7. [320558]. https://doi.org/10.1136/archdischild-2020320558

Published in:

Archives of Disease in Childhood

Document Version:

Peer reviewed version

Queen's University Belfast - Research Portal:

Link to publication record in Queen's University Belfast Research Portal

Publisher rights

Copyright 2020 BMJ.

This is an open access Creative Commons Attribution-NonCommercial License (https://creativecommons.org/licenses/by-nc/4.0/), which permits use, distribution and reproduction for non-commercial purposes, provided the author and source are cited.

\section{General rights}

Copyright for the publications made accessible via the Queen's University Belfast Research Portal is retained by the author(s) and / or other copyright owners and it is a condition of accessing these publications that users recognise and abide by the legal requirements associated with these rights.

Take down policy

The Research Portal is Queen's institutional repository that provides access to Queen's research output. Every effort has been made to ensure that content in the Research Portal does not infringe any person's rights, or applicable UK laws. If you discover content in the Research Portal that you believe breaches copyright or violates any law, please contact openaccess@qub.ac.uk. 


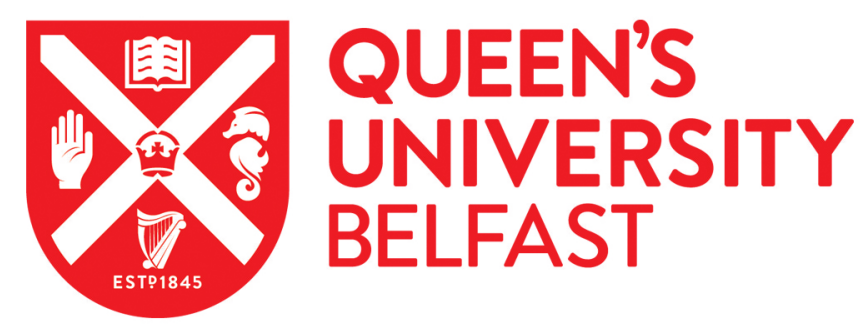

\section{Seroprevalence of SARS-CoV-2 antibodies in children: a prospective multicentre cohort study}

Waterfield, T. (Accepted/In press). Seroprevalence of SARS-CoV-2 antibodies in children: a prospective multicentre cohort study. Archives of Disease in Childhood.

Published in:

Archives of Disease in Childhood

Document Version:

Peer reviewed version

Queen's University Belfast - Research Portal:

Link to publication record in Queen's University Belfast Research Portal

Publisher rights

(c) 2020 Author(s) (or their employer(s)) No commercial

re-use

This work is made available online in accordance with the publisher's policies. Please refer to any applicable terms of use of the publisher.

\section{General rights}

Copyright for the publications made accessible via the Queen's University Belfast Research Portal is retained by the author(s) and / or other copyright owners and it is a condition of accessing these publications that users recognise and abide by the legal requirements associated with these rights.

Take down policy

The Research Portal is Queen's institutional repository that provides access to Queen's research output. Every effort has been made to ensure that content in the Research Portal does not infringe any person's rights, or applicable UK laws. If you discover content in the Research Portal that you believe breaches copyright or violates any law, please contact openaccess@qub.ac.uk. 


\section{Seroprevalence of SARS-CoV-2 antibodies in children - A prospective multicentre cohort study.}

Authors and institutions

1. Thomas Waterfield

2. Chris Watson

a. Centre For Experimental Medicine, Wellcome Wolfson Institute of Experimental Medicine, Queen's University Belfast, Belfast, UK

a. Centre For Experimental Medicine, Wellcome Wolfson Institute of

3. Rebecca Moore Experimental Medicine, Queen's University Belfast, Belfast, UK

a. Royal Belfast Hospital for Sick Children, Belfast, UK

4. Kathryn Ferris

a. Royal Belfast Hospital for Sick Children, Belfast, UK

5. Claire Tonry

a. Centre For Experimental Medicine, Wellcome Wolfson Institute of

6. Alison P Watt

Experimental Medicine, Queen's University Belfast, Belfast, UK

7. Claire McGinn

a. Regional Virus Laboratory, Belfast Health and Social Care Trust, Belfast, UK

a. Royal Belfast Hospital for Sick Children, Belfast, UK

8. Steven Foster

a. Royal Hospital for Children, Glasgow, UK

9. Jennifer Evans

a. Cardiff and Vale University Health Board, Cardiff, UK

10. Mark D Lyttle

a. Emergency Department, Bristol Royal Hospital for Children, Bristol, UK

b. Faculty of Health and Applied Sciences, University of the West of England, Bristol, UK

11. Shazaad Ahmad

a. Department of Virology, Manchester Medical Microbiology Partnership, Manchester Foundation Trust

b. Manchester Academic Health Sciences Centre, Manchester, UK

12. Shamez Ladhani

a. Immunisation and Countermeasures Division, Public Health England, London

13. Michael Corr

a. Belfast Health and Social Care Trust, Belfast, UK

14. Lisa McFetridge

a. Mathematical Sciences Research Centre, Queen's University Belfast, Belfast, UK

15. Hannah Mitchell

a. Mathematical Sciences Research Centre, Queen's University Belfast, Belfast, UK

16. Kevin Brown

a. Virus Reference Department, Public Health England, London

17. Gayatri Amirthalingam

a. Immunisation and Countermeasures Division, Public Health England, London

18. Julie-Ann Maney

a. Emergency Department, Royal Belfast Hospital for Sick Children, Belfast, UK

19. Sharon Christie

a. Royal Belfast Hospital for Sick Children, Belfast, UK

Corresponding author - Thomas Waterfield - Centre For Experimental Medicine, Wellcome Wolfson Institute of Experimental Medicine, Queen's University Belfast, Belfast, UK

t.waterfield@qub.ac.uk 


\section{Abstract \\ Background}

Studies based on molecular testing of oral/nasal swabs underestimate severe acute respiratory syndrome coronavirus 2 (SARS-CoV-2) infection due to issues with test sensitivity, test timing and selection bias. The objective of this study was to report the presence of SARSCoV-2 antibodies, consistent with previous infection.

\section{Design}

This multicentre observational cohort study, conducted between $16^{\text {th }}$ April - $3^{\text {rd }}$ July 2020 at 5 UK sites, recruited children of healthcare workers, aged 2 to 15 years of age. Participants provided blood samples for SARS-CoV-2 antibody testing and data were gathered regarding unwell contacts and symptoms.

\section{Results}

1007 participants were enrolled, and 992 were included in the final analysis. The median age of participants was $10 \cdot 1$ years. There were $68(6.9 \%)$ participants with positive SARS-CoV-2 antibody tests indicative of previous SARS-CoV-2 infection. Of these, 34/68 (50\%) reported no symptoms prior to testing. The presence of antibodies and the mean antibody titre was not influenced by age. Following multivariable analysis four independent variables were identified as significantly associated with SARS-CoV-2 seropositivity: known infected household contact $\mathrm{OR}=10.9(95 \% \mathrm{Cl}: 6.1$ to 19.6$)$; fatigue $\mathrm{OR}=16.8(95 \% \mathrm{Cl}: 5.5$ to 51.9$)$; gastrointestinal symptoms $\mathrm{OR}=6.6(95 \% \mathrm{Cl} 3.0$ to 13.8$)$; and changes in sense of smell or taste $\mathrm{OR}=10.0(95 \%$ Cl: 2.4 to 11.4$)$.

\section{Discussion}

Children demonstrated similar antibody titres in response to SARS-CoV-2 irrespective of age. Fatigue, gastrointestinal symptoms and changes in sense of smell or taste were the symptoms most strongly associated with SARS-CoV-1 antibody positivity.

\section{Registration}

https://www.clinicaltrials.gov (trial registration: NCT0434740) on the 15/04/2020. 


\section{Introduction}

During the first wave of the severe acute respiratory syndrome coronavirus 2 (SARS-CoV-2) pandemic in England, children accounted for just 1\% of confirmed infections,(1) had a milder clinical course, and had a much lower mortality than adults (1-4), a pattern similar to other international settings $(3,4)$. The reasons for this are unknown, but various hypotheses exist. Public health measures, such as school closures, may have minimised children's exposure to SARS-CoV-2. It is also possible that children have a different immune response to the virus for example reduced expression of the ACE2 gene, the host receptor for SAR-CoV-2 virus in airway cells (5-7).

Despite existing data, it is impossible to state accurately what proportion of children were infected with SARS-CoV-2 in the UK. Studies based on molecular testing of oral/nasal swabs with real-time reverse transcription polymerase chain reaction (RT-qPCR) underestimate infection due to issues with test sensitivity, timing of testing and selection bias due to only symptomatic individuals undergoing testing (8). A potentially more reliable method is to test for specific antibodies. Existing antibody tests typically detect immunoglobulin G (IgG or Total antibody) to either the nucleocapsid or spike proteins of the virus (9). Antibody testing has greater potential than RT-qPCR to detect previous asymptomatic/mildly symptomatic infection, and is not dependent on coinciding with active infection. Current best seroprevalence estimates from adults in the UK indicate that approximately $6.2 \%$ have antibodies consistent with previous SARS-CoV-2 infection (10). These findings are similar to other domestic and international seroprevalence studies (11-14).

It is unclear what proportion of children are asymptomatic and which symptoms are most associated with paediatric SARS-CoV-2 infection. Estimates based on RT-qPCR testing of oral/nasal swabs suggest that cough or fever are the most common symptoms (15-20). However, these studies focus on symptomatic cohorts, introducing selection bias (15-20), which leads to underestimation of the asymptomatic proportion. 
The objective of this study was to report the presence, and titres, of SARS-CoV-2 antibodies in healthy children of healthcare workers across the UK and to report the symptomatology of infection including the asymptomatic rate. 


\section{Methods}

Study Design

This multicentre observational prospective cohort study was designed to determine the seroprevalence of SARS-CoV-2 antibodies in healthy children, and report the symptomatology of infection. This study has been written in conjunction with the Strengthening the Reporting of Observational Studies in Epidemiology (STROBE) guidelines (21). The study protocol has undergone external peer review and is available as an open access publication (22).

\section{Setting}

Participants were recruited from 5 UK centres, in the 4 regions of the UK, between $16^{\text {th }}$ April 2020 and $3^{\text {rd }}$ July 2020. The sites included tertiary NHS hospitals (Belfast, Cardiff, Manchester, and Glasgow) and a Public Health England site (London).

\section{Participants}

Children of healthcare workers, aged between 2 and 15 years at the time of recruitment, were eligible to participate. A "healthcare worker" was defined as a National Health Service (NHS) employee. Healthcare workers were categorised according to role, including whether that role involved patient facing activities. Approximately 150 non-patient facing staff were included to provide a comparison group, and to improve the generalisability of the results. Participants were identified at each participating NHS organisation using internal intranet advertisements and email circulars. Children were excluded if they were receiving antibiotics, had been admitted to hospital within the last 7 days, were receiving oral immunosuppressive treatment, or if ever diagnosed with a malignancy.

\section{Informed consent}

Informed consent was obtained, and assent given by children where possible. Participants were free to decline/withdraw consent at any time without providing a reason and without being subject to any resulting detriment. 
Assessments and procedures

All children underwent phlebotomy performed by experienced paediatric medical and nursing professionals. Serum and/or plasma were tested for antibodies to SARS-CoV-2, in UKAS accredited laboratories using the following assays, which have been validated for use in adults (23-25):

- Nucleocapsid assays - (Abbott Architect ${ }^{\circledR}$ SARS-CoV-2 IgG and Roche Elecsys ${ }^{\circledR}$ Anti-SARS-CoV-2 Total Antibody)

- $\quad$ Spike protein assays - (DiaSorin LIAISON® SARS CoV-2 S1/S2 IgG assay)

The Abbott, Roche and DiaSorin assays are highly specific for SARS-CoV-2 antibodies, using the manufacturer's suggested cut-offs, with specificities of 1.00 ( $95 \% \mathrm{Cl} 0.98$ to 1.00$), 1.00$ (95\% Cl 0.99 to 1.00$)$ and $0.98(95 \% \mathrm{Cl} 0.96$ to 0.99$)$ respectively (23-25). They do however have lower sensitivities at $0.94(95 \% \mathrm{Cl} 0.86$ to 0.98$), 0.84(95 \% \mathrm{Cl} 0.75$ to 0.91$)$ and 0.64 $(95 \% \mathrm{Cl} 0.54$ to 0.73$)$ respectively (23-25). A summary of the tests used is provided in Table 1.

Study data were collected on a case report form (CRF) using REDCap (Research Electronic Data Capture) electronic data capture tools (26). Participants and their parents provided information at enrollment relating to age, sex, previous health and potential predictors of SARS-CoV-2 seropositivity including; known contact with individuals with COVID-19, contact with individuals who have been symptomatic and/or self-isolating and results of any diagnostic testing such as RT-qPCR testing/antibody testing. Participants and their parents also reported any symptoms and illness episodes since the onset of the pandemic in March but prior to the first clinic appointment. Data was collected relating to symptoms but not relating to time of onset or duration of illness. To minimise recall bias, data relating to exposures and illness episodes were collected blinded to antibody testing results. Copies of the CRFs used at enrollment can be found in the supplementary material. 
Primary Outcome Measures

- Presence of antibodies (IgG/Total antibody) to SARS-CoV-2 in serum or plasma reported as titres.

- SARS-CoV-2 seropositivity defined as a positive antibody test using the manufacturer's advised positivity cut-off.

\section{Secondary Outcome Measure}

- Predictors of SARS-CoV-2 positivity including reported symptoms.

\section{Sample Size Justification}

The study was powered to detect a change in seroprevalence of SARS-CoV-2 antibodies at 3 time-points (enrollment, and 2 and 6 months following enrollment). To achieve this, 675 participants were required (assuming alpha of, 0.05 and beta of 0.2 ). Allowing for $30 \%$ dropout rate, we aimed to recruit 900 participants from 5 sites. The data presented in this study reflects only the data collected at enrollment and the study is ongoing.

\section{Statistical analysis plan}

Variables including sex, age, parent role, symptomatology, household contacts, and SARSCoV-2 antibody prevalence were analysed using descriptive statistics (number and proportion for discrete variables, median and interquartile range for continuous variables). Seroprevalence rates between sites were compared using Fisher's exact test and antibody titres were correlated with age using the Kendall's rank correlation test and mean titres were compared between symptomatic and asymptomatic participants using the Wilcoxon rank sum test.

Variables associated with SARS-CoV-2 positivity were analysed using univariate and multivariable analyses to identify predictors of SARS-CoV-2 seropositivity. Initially all possible variables were assessed using univariate analysis with Fisher's exact testing of categorical 
data, and the Mann-Whitney $U$ test for continuous data (continuous data were skewed). All variables were then included in a weighted binary multivariable logistic regression model. Participants with incomplete CRFs were excluded from univariate and multivariable analysis. Analysis was conducted in R (R Core Team, 2014).

Patient and Public Involvement (PPI)

A PPI group comprising parents and children was convened. The PPI group met virtually and via socially distanced meetings. The group contributed to the design of the study through online surveys and video discussions. They have also contributed to media interviews on national television and the lead young person has co-authored a manuscript outlining their experience of taking part in the study (27).

Office for Research Ethics Committees (OREC) and local Research Governance Ethical approval was obtained from the London - Chelsea Research Ethics Committee (REC Reference - 20/HRA/1731) and the Belfast Health \& Social Care Trust Research Governance (Reference 19147TW-SW).

\section{Study Registration}

This study was registered at https://www.clinicaltrials.gov (trial registration: NCT0434740) on the $15 / 04 / 2020$ (last updated 27/05/20). At the time of registration no patients had been recruited to the study which opened on the $16 / 04 / 20$. The end of the study will be the last study visit. 


\section{Findings}

In total, 1042 potential participants were screened for inclusion, of whom 35 were excluded; 18 were outside the specified age range, 1 met specific exclusion criteria, and 16 declined consent. The remaining 1007 children were enrolled, of which 15 were excluded from analysis due to unsuccessful phlebotomy; 992 were included in the final analysis (Figure 1). The recruitment by site is shown in Table 2 . In the analysis cohort 962/992 (97\%) had complete CRFs and 30/992 (3\%) had partially complete CRFs.

The median age of participants was $10 \cdot 1$ years (range 2.03 to 15.99 years), with $484(49 \%)$ aged under 10 years; 509 (51\%) were male. The roles of participant's parents are shown in Figure 2. There were 359/992 (36.2\%) children of hospital medical staff, 191/992 (19.3\%) children of hospital nursing/midwifery staff, 95/992 (9.6\%) children of community medical staff, $36 / 992(3.6 \%)$ children of community nursing staff and 160/992 (16.1\%) children of other patient facing staff such as radiographers, physiotherapists and other allied healthcare professionals. There were $151 / 992(15.2 \%)$ children of non-patient facing staff such as managerial and administrative staff.

There were 68/992 participants with positive SARS-CoV-2 antibodies, giving a seroprevalence of $6.9 \%$ (95\% Cl 5.4 to $8.6, n=992)$. Of those with positive SARS-CoV-2 antibody tests, 34/68 (50\%) reported no symptoms. The most commonly reported symptoms associated with SARSCoV-2 seropositivity were fever 21/68 (31\%), gastrointestinal symptoms (diarrhoea, vomiting and abdominal cramps) 13/68 (19\%) and headache 12/68 (18\%). The presence of fever, cough or changes in a sense of smell/taste were recorded in $26 / 68(38 \%)$ of participants. No children within this cohort had severe disease requiring hospital admission. A summary of reported symptoms and their frequency can be seen in Table 3.

Seroprevalence of SARS-CoV-2 antibodies varied between sites. Belfast had significantly lower seroprevalence than all other sites at $0.9 \%(95 \% \mathrm{Cl} 0.2$ to $3.3, n=215) ; p<0.0001$, and 
in London seroprevalence was significantly higher than all other sites at $11.6 \%(95 \% \mathrm{Cl} 7.8$ to $16.8 n=199) ; p=0.0069$. The remaining 3 sites reported seroprevalence rates between $5.6 \%$ and $8.9 \%$. The difference between these 3 sites were not statistically significant (Table 2).

The mean antibody titres, for those testing positive, were;

- 4.86 Calculated index $\mathrm{S} / \mathrm{C}(95 \% \mathrm{Cl} 4.28$ to $5.45, \mathrm{n}=58)$ for the Abbott Architect $\AA$ SARS-CoV-2 IgG assay.

- 65.32 cut-off index $\mathrm{COI}(95 \% \mathrm{Cl} 43.24$ to $87.40, \mathrm{n}=31)$ for the Roche Elecsys ${ }^{\circledR}$ AntiSARS-CoV-2 Total Antibody assay.

- $64.17 \mathrm{AU} / \mathrm{ml}(95 \% \mathrm{Cl} 37.99$ to $90.36, \mathrm{n}=31)$ for the DiaSorin LIAISON® SARS CoV-2 $\mathrm{S} 1 / \mathrm{S} 2 \lg \mathrm{G}$ assay.

There was no correlation between age and antibody titres (Figure 3). The results from the Abbott Architect $\circledast$ SARS-CoV-2 IgG assay indicated a small but significant difference in mean antibody titres between asymptomatic $4.3 \mathrm{~S} / \mathrm{C}(95 \% \mathrm{Cl} 3.4$ to 5.2$)$ and symptomatic participants $5.5 \mathrm{~S} / \mathrm{C}(95 \% \mathrm{Cl} 4.7$ to 6.2$) ; p=0.04$. There was no significant difference in mean antibody titres for the Roche Elecsys ${ }^{\circledR}$ or DiaSorin LIAISON $₫$ assays when comparing symptomatic and asymptomatic participants ( $p=0.23$ and 0.58 respectively) (Figure 3 ). A table of concordance between the three assays used is available in the supplementary material.

The univariate analysis of individual variables associated with SARS-CoV-2 seropositivity is shown in Table 3. In addition to clinical features, variables such as age, gender, the role of the parent (patient facing or not) and known household contacts were included. Age and gender were not significantly associated with SARS-CoV-2 seropositivity (Table 3). Parental role showed significant association in the univariate analysis, but this was no longer significant once corrected for site and other variables in the multivariable analysis. Contact with a household member with confirmed SARS-CoV-2 infection was significantly associated with SARS-CoV-2 seropositivity in the participant in both the univariate and multivariable analyses 
(Table 3). The multivariable analysis identified 4 variables independently associated with SARS-CoV-2 seropositivity: (i) known household contact with confirmed SARS-CoV-2 ( $p<0.0001)$, (ii) fatigue ( $p=0.001)$, (iii) gastrointestinal symptoms $(p=0.0001)$, and (iv) changes in sense of smell or taste $(p<0.0012)$. 


\section{Interpretation}

This observational study is one of the largest UK studies of paediatric SARS-CoV-2 antibody seroprevalence, and the only study to recruit from all regions of the UK. Following the first pandemic wave in the UK, 68/992 (6.9\%) children of healthcare workers had evidence of prior infection with SARS-CoV-2. Whilst this is likely to be higher than the general population it is surprisingly similar to the seroprevalence reported by the Office for National Statistics (ONS) study of adults from England and Wales (6.2\%) (10), and similar to international estimates $(11-13)$. As expected there was marked geographical variation, with London reporting the highest seropositivity rates $(11.6 \%)$ and Belfast the lowest $(0.9 \%) p<0.0001$. These regional variations are consistent with published adult estimates of seroprevalence from the same time period (10).

In this study there was a near equal number of children under 10 years of age $32 / 68(47 \%)$ and children over 10 years of age 36/68 (53\%) developing antibodies consistent with previous SARS-CoV-2 infection. Age, as a categorical or continuous variable, was not a statistically significant factor in predicting the presence of antibodies, or the overall titres in children irrespective of the assay used (Figure 3).

Of the 68 participants with positive antibody tests, $34 / 68(50 \%)$ reported no symptoms. The most commonly reported symptoms associated with SARS-CoV-2 seropositivity were fever $(21 / 68) 30 \%$ and gastrointestinal symptoms $13 / 68(19 \%)$. These symptoms, in addition to fatigue, and changes in sense of smell or taste, were independently associated with previous SARS-CoV-2 seropositivity based on the weighted binary multivariable regression modelling. These findings reflect a number of international studies (15-20). Current UK testing strategies directing testing only for those with fever, cough or changes in smell/taste would have identified $26 / 34(76 \%)$ of symptomatic participants in this study (assuming $100 \%$ sensitivity and specificity of RT-qPCR swab testing). Adding gastrointestinal symptoms would have 
identified nearly all symptomatic cases in this cohort 33/34(97\%). It is however, important to note that the predictive value of individual symptoms is context dependent and their utility will vary dependent upon the season and the symptomatology of other circulating infections. These findings may be useful to policy makers when considering the best approach to screening paediatric populations for SARS-CoV-2.

There is evidence from adult serological studies that those with severe illness develop a significantly greater antibody response than those with mild or asymptomatic disease (28-30). This has raised concerns that children, who typically have mild disease, may fail to develop a meaningful antibody response to SARS-CoV-2 infection. More recently, emerging adult data suggest that even asymptomatic adults are capable of mounting a potentially lasting and protective immune response (31-32). In our study antibody titres, measured using the Abbott Architect $\AA$ SARS-CoV-2 IgG assay, were significantly higher in symptomatic children compared with asymptomatic children $p=0.04$. These findings were not replicated with either the Roche Elecsys ${ }^{\circledR}$ Anti-SARS-CoV-2 or DiaSorin LIAISON® SARS CoV-2 S1/S2 IgG assays. It therefore remains unclear to what extent the severity of symptoms in children influences the antibody response. 


\section{Strengths/Limitations}

The strengths of this study are that it is a large multicentre study including children from across the four nations of the UK. The findings are based on systematically screening children for SARS-CoV-2 antibodies and this removes selection bias from the assessment of the asymptomatic proportion and determine symptomatology.

The limitations of this study are:

- The SARS-CoV-2 antibody tests have not been validated for use in children

- The absolute sample size of seropositive participants is relatively small

- There was selection bias towards children of hospital staff and children with only mild disease.

- There is a risk of recall bias due to the retrospective nature of data collection relating to symptomatology.

\section{Summary}

This study demonstrates that approximately half of children with positive antibody tests for SARS-CoV-2 reported no symptoms. This study also demonstrates that younger children were just as likely to have SARS-CoV-2 antibodies as older children and that they are capable of mounting a similar antibody response. 
What is known about this topic?

- Children are relatively unaffected by the SARS-CoV-2 infection with very few requiring hospitalisation.

- A large, but unknown proportion of children with SARS-CoV-2 infection are asymptomatic.

- Molecular testing of oral/nasal swabs underestimates SARS-CoV-2 infection.

\section{What this study adds}

- Gastrointestinal upset is a relatively common symptom of Covid-19 in children. Adding gastrointestinal upset to the list of symptoms triggering a test in children would improve case-finding.

- Asymptomatic and mildly symptomatic children are capable of developing an antibody response to SARS-CoV-2.

- This study did not find a difference in rates of seropositivity or antibody responses according to age in the children of healthcare workers. 


\section{Declarations}

- Ethical approval was obtained from the London - Chelsea Research Ethics Committee (REC Reference - 20/HRA/1731) and the Belfast Health \& Social Care Trust Research Governance (Reference 19147TW-SW).

- Declaration of interests: None declared.

- Funding: This work was supported by HSC R\&D Division, Public Health Agency Ref: COM/5596/20. This funding source had no role in the design of this study and will not have any role during its execution, analyses, interpretation of the data, or decision to submit result.

- Authors contributions: Dr Waterfield, Dr Watson, Dr Ladhani and Dr Christie conceived the study idea. Dr Waterfield, Dr Watson, Dr Ladhani, Dr Christie, Dr Moore, Dr Ferris, Dr McGinn, Dr Foster, Dr Evans, Dr Lyttle, Dr Ahmad, Dr Ladhani, Dr Corr, Dr McFetridge, Dr Mitchell and Dr Maney contributed to the design of the study. Dr Waterfield co-ordinated the running of the study including data management and site training. Dr Corr wrote the study protocol. Dr Lyttle designed the electronic CRFs. Dr Moore co-ordinated and led the PPI group. Dr Christie, Dr Ferris, Dr Foster, Dr Evans, Dr Ahmad and Dr Ladhani were site leads. Dr Tonry, Dr Watson, Dr Amirthalingam, Dr Brown and Dr Watt were responsible for performing laboratory testing. Dr McFetridge and Dr Mitchell provided statistical expertise and performed the statistical analysis. All authors contributed to the writing of the manuscript.

- Acknowledgements: We thank all of the children and their families who participated in this study. We also thank all of the sites (Belfast Health and Social Care Trust, The Ulster Independent Clinic, Cardiff and Vale University Health Board, NHS Greater Glasgow and Clyde, Public Health England, London, Manchester University NHS Foundation Trust, NIHR Manchester Clinical Research Facility) and staff who participated in screening and enrolment. We also thank St Jude's Children's Cancer Aid and Research Institute for providing artwork for the participant information sheet. 
Individual thanks to Elizabeth Waxman, Derek Fairley, Gala Roew-Setz, James McKenna, Peter Mallet, Ryan Chrisite, Katherine Christie, Emma McManus, Christian Bennison, Kate Mullan and Aleksandra Metryka.

- Data Sharing: All of the individual participant data collected during this study will be available (including data dictionaries) on the Queen's University Belfast database within 3 months of completion of the study. 


\section{References}

1. Ladhani SN, Amin-Chowdhury Z, Davies HG, et alCOVID-19 in children: analysis of the first pandemic peak in EnglandArchives of Disease in Childhood Published Online First: 12 August 2020. doi: 10.1136/archdischild-2020-320042

2. Lipsitch M, Swerdlow DL, Finelli L. Defining the Epidemiology of Covid-19 - Studies Needed. N Engl J Med 2020;382:1194-6.

3. Coronavirus Disease 2019 in Children-United States, February 12-April 2, 2020. MMWR Morb Mortal Wkly Rep 2020; 69: 422-26. 2

4. Children and COVID-19. Amsterdam: National Institute for Public Health and the Environment (RIVM), 2020. https://www.rivm.nl/en/novelcoronavirus-covid19/children-and-covid-19 (May 5, 2020).

5. Bunyavanich S, Do A, Vicencio A. Nasal Gene Expression of Angiotensin-Converting Enzyme 2 in Children and Adults. JAMA 2020.

6. Li Y, Zhou W, Yang L, et al. Physiological and pathological regulation of ACE2, the SARS142 CoV-2 receptor. Pharmacological Research 2020; 157: 104833.143

7. Bourgonje AR, Abdulle AE, Timens $W$, et al. Angiotensin-converting enzyme-2 (ACE2), 144 SARS-CoV-2 and pathophysiology of coronavirus disease 2019 (COVID-19). The Journal of 145 Pathology; n/a. DOI: 10.1002/path.5471.

8. Bullis SM, Crothers JW, Wayne S, et al. A cautionary tale of false-negative nasopharyngeal COVID-19

testing. IDCases 2020;20:e00791. doi:10.1016/j.idcr.2020.e00791 pmid:http://www.n cbi.nlm.nih.gov/pubmed/32377507

9. Public Health England. COVID-19: PHE laboratory assessments of molecular tests. https://www.gov.uk/government/publications/covid-19-phe-laboratory-assessmentsof-molecular-tests

10. Latest data and analysis on coronavirus (COVID-19) in the UK and its effect on the economy and society. Office for National Statistics.

https://www.ons.gov.uk/peoplepopulationandcommunity/healthandsocialcare/conditio nsanddiseases

11. Pollán $M$, Pérez-Gómez $B$, Pastor-Barriuso R, Oteo J, Hernán MA, Pérez-Olmeda $M$, et al. Prevalence of SARS-CoV-2 in Spain (ENE-COVID): a nationwide, populationbased seroepidemiological study. Lancet 2020;0. doi:10.1016/S01406736(20)31483-5.

12. Stringhini S, Wisniak A, Piumatti G, Azman AS, Lauer SA, Baysson $\mathrm{H}$, et al. Seroprevalence of anti-SARS-CoV-2 IgG antibodies in Geneva, Switzerland (SEROCoV-POP): a population-based study. Lancet 2020. doi:10.1016/S01406736(20)31304-0

13. Pagani G, Conti F, Giacomelli A, Bernacchia D, Rondanin R, Prina A, et al. Seroprevalence of SARS-CoV-2 IgG significantly varies with age: results from a mass population screening (SARS-2-SCREEN-CdA). MedRxiv 2020:2020.06.24.20138875. doi:10.1101/2020.06.24.20138875/

14. What's the Story - PHE England. https://assets.publishing.service.gov.uk/government/uploads/system/uploads/attach ment data/file/916993/Weekly COVID19 Surveillance Report week 37 FINAL.pdf

15. Dong Y, Mo X, Hu Y, et al. Epidemiology of COVID-19 Among Children in China. Pediatrics. Mar 162020.

16. Liu W, Zhang Q, Chen J, et al. Detection of Covid-19 in Children in Early January 2020 in Wuhan, China. N Engl J Med. Apr 2 2020;382(14):1370-1371. 
17. Lu X, Zhang L, Du H, et al. SARS-CoV-2 Infection in Children. N Engl J Med. Apr 23 2020;382(17):1663-1665.

18. Parri N, Lenge M, Buonsenso D. Children with Covid-19 in Pediatric Emergency Departments in Italy. N Engl J Med. May 12020.

19. Qiu H, Wu J, Hong L, Luo Y, Song Q, Chen D. Clinical and epidemiological features of 36 children with coronavirus disease 2019 (COVID-19) in Zhejiang, China: an observational cohort study. Lancet Infect Dis. Mar 252020.

20. Tagarro A, Epalza C, Santos M, et al. Screening and Severity of Coronavirus Disease 2019 (COVID-19) in Children in Madrid, Spain. JAMA Pediatr. Apr 82020.

21. von Elm E, Altman DG, Egger M, Pocock SJ, Gøtzsche PC, Vandenbroucke JP; STROBE Initiative. The Strengthening the Reporting of Observational Studies in Epidemiology (STROBE) statement: guidelines for reporting observational studies. Lancet. 2007 Oct 20;370 (9596):1453-7.

22. Waterfield T et al. Seroprevalence of SARS-CoV-2 antibodies in children of healthcare workers- A prospective multicentre cohort study protocol - Accepted for publication August 2020.

23. Public Health England. Evaluation of the Abbott SARS-CoV-2 IgG for the detection of anti-SARSCoV-2 antibodies.

https://assets.publishing.service.gov.uk/government/uploads/system/uploads/attach ment_data/file/890566/Evaluation_of_Abbott_SARS_CoV_2_lgG_PHE.pdf

24. Public Health England. Evaluation of Roche Elecsys AntiSA $\bar{R} S-\overline{C o}-2$ serology assay for the detection of anti-SARS-CoV-2 antibodies.

https://assets.publishing.service.gov.uk/government/uploads/system/uploads/attach ment_data/file/891598/Evaluation_of_Roche_Elecsys_anti_SARS_CoV_2_PHE_200 610_v8.1_FINAL.pdf

25. Public Health England. Evaluation of DiaSorin LIAISON SARSCoV-2 S1/S2 IgG serology assay for the detection of anti-SARS-CoV-2 antibodies https://assets.publishing.service.gov.uk/government/uploads/system/uploads/attach ment_data/file/893435/Evaluation_of_Diasorin_Liaison_anti_SARS_CoV_2.pdf

26. Harris PA, Taylor R, Thielke R, Payne J, Gonzalez N, Conde JG. Research electronic data capture (REDCap) - A metadata-driven methodology and workflow process for providing translational research informatics support. J Biomed Inform [Internet]. 2009 Apr [cited 2019 Oct 17];42(2):377-81. Available from: http://www.ncbi.nlm.nih.gov/pubmed/18929686

27. $\mathrm{R}$ Moore et al. Listening to the voices of children and young people involved in medical research. Submitted to ADC August 2020.

28. Choe, P.G., Kang, C.K., Suh, et al. Early Release - Antibody Responses to SARSCoV-2 at 8 Weeks 552 Postinfection in Asymptomatic Patients - Volume 26, Number 10-October 2020 - Emerging 553 Infectious Diseases journal - CDC.

29. Long, Q.-X., Liu, B.-Z., Deng, H.-J., et al. 603 Y., Cai, X.-F., et al. (2020b). Antibody responses to SARS-CoV-2 in patients with COVID-19.604 Nat Med 26, 845-848.

30. Qu, J., Wu, C., Li, X., Zhang, G., Jiang, Z., Li, X., Zhu, Q., and Liu, L. (2020). Profile of $623 \mathrm{Immunoglobulin} G$ and IgM Antibodies Against Severe Acute Respiratory Syndrome 624 Coronavirus 2 (SARS-CoV-2). Clinical Infectious Diseases

31. Sekine, T., Perez-Potti, A., Rivera-Ballesteroset al. Robust T cell immunity in convalescent individuals with asymptomatic or mild COVID-19, Cell (2020), doi: https://doi.org/10.1016/j.cell.2020.08.017.

32. TJ Ripperger, JL Uhrlaub, M Watanabe, et al. etection, prevalence, and duration of humoral responses to SARS-CoV-2 under conditions of limited population exposure doi: https://doi.org/10.1101/2020.08.14.20174490 
Figure 1: Flow of children of healthcare workers through the study

Figure 2: Summary of participants parent's roles

Figure 3: Scatter diagrams of age/symptoms in children of healthcare workers and SARSCoV-2 assay titre. Abbott Architect ${ }^{\circledR}$ reported in S/C, Roche Elecsys $\AA$ reported in COI, DiaSorin LIAISON® reported in AU/mI. 
Table 1: Summary of antibody tests used

\begin{tabular}{|c|c|c|c|}
\hline Name of assay & Target & Units & Cut-Off \\
\hline Abbott Architect $\circledast$ SARS-CoV-2 lgG & Nucleocapsid & $\begin{array}{l}\text { Calculated index } \\
\text { S/C }\end{array}$ & $1.4 \mathrm{~S} / \mathrm{C}$ \\
\hline Roche Elecsys ${ }^{\circledR}$ Anti-SARS-CoV-2 & Nucleocapsid & $\begin{array}{l}\text { Cut-off index } \\
\text { COI }\end{array}$ & $1.0 \mathrm{COI}$ \\
\hline DiaSorin LIAISON® SARS CoV-2 S1/S2 IgG assay & Spike protein & $\begin{array}{l}\text { Arbitrary units } \\
\mathrm{AU} / \mathrm{ml}\end{array}$ & 15.0 AU/ml \\
\hline
\end{tabular}

Table 2: Recruitment summary of children of healthcare workers and seroprevalence by site ( $\mathrm{n}$ and (\%) unless otherwise stated)

\begin{tabular}{ccccc}
\hline Site & Screened & Included Participants & Antibody Positive & $\%^{*}$ \\
\hline Belfast & 217 & 215 & 2 & $0.9(0.2$ to 3.3$)$ \\
\hline Cardiff & 192 & 178 & 10 & $5.6(3.1$ to 10.0$)$ \\
\hline Glasgow & 229 & 224 & 20 & $8.9(5.9$ to 13.4$)$ \\
\hline London & 215 & 199 & 23 & $11.6(7.8$ to 16.8$)$ \\
\hline Manchester & 189 & 176 & 13 & $7.4(4.4$ to 12.2$)$ \\
\hline Total & 1042 & 992 & 68 & 6.9 (5.4 to 8.6$)$ \\
\hline
\end{tabular}

*(95\% Confidence Intervals) 
Table 3: Univariate analysis of variables for SARS-CoV-2 Antibodies in children of healthcare workers (Fisher's Exact for categorical variables, Mann-Whitney U for continuous variables). Number and (\%) with feature shown for categorical variables and median for continuous variables unless otherwise stated.

Without SARS-

CoV-2 Antibodies

$N(\%)$

\begin{tabular}{|c|c|c|c|c|c|}
\hline Median age (years) & 992(100) & $10.1(5.8)$ & $10.2(6.9)$ & - & 0.481 \\
\hline Aged 10 years and over & $992(100)$ & 472(51) & $36(53)$ & $1.1(0.6$ to 1.8$)$ & 0.802 \\
\hline Male gender & 991(99.9) & $468(51)$ & $41(60)$ & $1.5(0.9$ to 2.5$)$ & 0.133 \\
\hline Parents (patient contact) & $992(100)$ & $789(85)$ & $52(76)$ & $0.6(0.3$ to 1.1$)$ & 0.055 \\
\hline Confirmed household contact & $960(97)$ & $63(7)$ & $30(44)$ & $10.9(6.1$ to 19.6$)$ & $<0.0001$ \\
\hline Fever & 962(97) & 102(11) & 21(31) & $3.5(1.9$ to 6.2$)$ & $<0.0001$ \\
\hline Gastrointestinal Symptoms & $962(97)$ & $31(3)$ & 13(19) & $6.6(3.0$ to 13.8$)$ & $<0.0001$ \\
\hline Headache & 962(97) & $34(4)$ & $12(18)$ & $5.4(2.4$ to 11.4$)$ & $<0.0001$ \\
\hline Lethargy/fatigue & 962(97) & $8(1)$ & $9(13)$ & $16.8(5.5$ to 51.9$)$ & $<0.0001$ \\
\hline Cough & 962(97) & $90(10)$ & $7(10)$ & $1.03(0.38$ to 2.3$)$ & 1.000 \\
\hline Change in sense of smell/taste & 962(97) & $7(1)$ & $5(7)$ & $10.0(2.4$ to 37.8$)$ & $<0.0008$ \\
\hline Myalgia/arthralgia & 962(97) & $21(2)$ & $5(7)$ & $3.3(0.94$ to 9.4$)$ & 0.031 \\
\hline Sore throat & $962(97)$ & $41(5)$ & $5(7)$ & $1.7(0.5$ to 4.4$)$ & 0.367 \\
\hline Shortness of breath & $962(97)$ & $13(1)$ & $3(4)$ & $3.1(0.6$ to 11.8$)$ & 0.098 \\
\hline Coryza & $962(97)$ & $27(3)$ & $1(1)$ & $0.5(0.0$ to 3.0$)$ & 0.715 \\
\hline Rash & 962(97) & 10(1) & 1(1) & $1.3(0.0$ to 9,5$)$ & 0.556 \\
\hline Conjunctivitis & 962(97) & $1(0)$ & $0(0)$ & $0.0(0.0$ to 508.7$)$ & 1.000 \\
\hline
\end{tabular}


